International Journal of Current Advanced Research

ISSN: O: 2319-6475, ISSN: P: 2319 - 6505, Impact Factor: SJIF: 5.995

Available Online at www.journalijcar.org

Volume 6; Issue 3; March 2017; Page No. 2699-2702

DOI: http://dx.doi.org/10.24327/ijcar.2017.2702.0081

Research Article

\title{
STATUS OF PARTIAL EDENTULISM AND ITS RESTORATION:A STUDY IN THE AGE GROUP OF 18-25 YEARS AMONG THE SUB-URBAN POPULATION OF KANCHIPURAM.
}

\author{
*Anjana Gopinath and Dr.Dhanraj
}

\author{
Saveetha Dental College and Hospitals, Poonamalle High Road, Chennai-77
}

\author{
A R T I C L E I I N F O \\ Article History: \\ Received $18^{\text {th }}$ December, 2016 \\ Received in revised form $16^{\text {th }}$ January, 2017 \\ Accepted $26^{\text {th }}$ February, 2017 \\ Published online $28^{\text {th }}$ March, 2017
}

\section{Key words:}

Prosthodontics, Partial Edentualism

\begin{abstract}
A B S T R A C T
Background: Replacement of missing teeth is a common patient need and with increase in life expectancy of individuals, the need for restoration of partially edentulous condition is increasing. Various studies have confirmed the prevalence of partial edentulousness, its rehabilitation status, lack of awareness,etc. Long-term partial edentulousness leads to various undesirable sequelae like aesthetic impairment, migration and spacing of surrounding teeth,etc. Hence decided to do a survey on status of partial edentulism and restoration of it.
\end{abstract}

Aim: To take a survey on the status of Partial Edentulism and its restoration which is a Cross Sectional Study in the Age Group of 18-25 Years among the sub-urban population of Kanchipuram.

Objective: The objective of this study is to find out the frequency of partial edentulism, its arch distribution status and awareness to restore among a population sample aged 18-25 years.

Materials and methods: In this study, a survey and a patient examination method was proposed. The population for the study comprised of the suburban population of Kanchipuram aged (18-25) years. All the subjects selected were screened using questionnaire and clinical examination.

Result: The incidence of partial edentulism among the surveyed group was $23 \%$ with no significant gender based difference in the frequency of its occurence. A predominance of partial edentulousness in maxillary posterior region in men and mandibular posterior region of women.Lack of awareness to go for rehabilitation was seen in both groups. However, women subjects showed more awareness than men did. All the subjects preferred to undergo fixed partial denture treatment rather than removable options.

conclusion: The prevalence of partial edentulism in the state population of suburban Kancheepuram is relatively high. The awareness about rehabilitation of partial edentulous state is also inadequate.Hence, more awareness and treatment program has to be initiated to address this concern.

Copyright $\odot 2017$ Anjana Gopinath and Dr. Dhanraj. This is an open access article distributed under the Creative Commons Attribution License, which permits unrestricted use, distribution, and reproduction in any medium, provided the original work is properly cited.

\section{INTRODUCTION}

Edentulism is defined as the absence or complete loss of all natural dentition (teeth). While tooth loss has long been considered an inevitable part of the ageing process, significant changes in oral disease patterns have occurred in the twentieth century relative to the rate of edentulism in the United States. Until the mid-twentieth century, much of dental care was devoted to tooth extraction.

\section{*Corresponding author: Anjana Gopinath}

I BDS, Saveetha Dental College and Hospitals, Poonamalle High Road, Chennai-77
Prevention of dental decay was unknown, and attempts to restore cavities were often painful. Tooth loss results from dental decay, gum disease (periodontitis), or accident. It can also reflect attitudes of the patient or provider, accessibility to dental care, or prevailing societal attitudes regarding oral health care. Edentulism is considerably less prevalent in higher than lower socioeconomic segments of the population.

Risk factors for edentulism include socioeconomic status, income, education level, and smoking. Edentulous individuals have been identified as being at greater risk for cardiovascular disease than are dentate individuals. Retention of fewer teeth in older adults has been correlated with poorer health, in contrast to greater tooth retention among people of the same age who report better general health. Replacement of missing 


\section{Status of partial edentulism and its restoration:a study in the age group of 18-25 years among the sub-urban population of kanchipuram.}

teeth has historically focused on the fabrication of complete dentures. Materials used in the earliest dentures ranged from carved ivory to animal bones. Often the results were only slightly better than being completely edentulous from a functional and an aesthetic view. Since the 1980s, the use of dental implants has begun to show promise for improving the retention of artificial teeth among those individuals healthy enough to be considered viable candidates.

Partial edentulism is the condition where in only few teeth of the dental arch are missing. This can be restored by using partial dentures or implants. Partial Edentulism affects approximately 158 million people globally as of $2010(2.3 \%$ of the population). It is more common in women at $2.7 \%$ compared to the male rate of $1.9 \%$. We do not have any statistics of percentage of population in India who are partially edentulous. So this study was carried out in suburban region of kanchipuram, Tamil Nadu.

Kanchipuram a otherwise known as Kanchi is a city in the Indian state of Tamil Nadu, $72 \mathrm{~km}$ (45 mi) from Chennai- the capital of Tamil Nadu. The city covers an area of $11.605 \mathrm{~km}$.According to 2011 census, the District had population of 39.90 lakh, which is about $5.53 \%$ of the total State population. The total population of the District was 39,90,897, in which 20,10,309 were Male and 19,80,588 were Female. In rural $14,53,072$ and in Urban it was $25,37,825$. The birth rate in the suburban area of Kanchipuram was 19.6 (per 1000 population) and death rate was 5.6 (per 1000 population).

\section{Aim And Objective}

The present study was conducted with following aims and objectives:

- $\quad$ To find out the frequency of partial edentulousness and its arch distribution status.

- Awareness to replace it.

- Ratio of removable to fixed among the restored cases.

- Gender difference in partial edentulism.

\section{MATERIALS AND METHODS}

An area based, cross sectional, epidemiological study on randomly selected population to determine the prevalence of partial edentulous patients in relation to age, gender and socioeconomic factors residing in the Sevilimedu area of suburban Kanchipuram. A total of 150 subjects were selected. The informed consent of each patient was taken prior to recording oral health. Subjects were selected on the basis of oral examination only. The criteria for selection of subjects in the study were:

- Individuals should be between age groups 1825years only.

- Only permanent dentition was considered.

- Third molar were excluded in the study.

- Questionnaire pro-forma:

A self administered questionnaire which sought inquiries related to sociodemographic factors which included name, age, sex, educational qualification, monthly income, reasons for edentulism (trauma, dental caries, periodontal disease, tobacco smoking, alcohol consumption, diabetes, hypertension, hyper/hypothyroidism, etc..) was prepared. Next part of the questionnaire elicited information regarding duration of partial edentulism with/without treatment, how often patient visits a dentist and why the teeth/tooth was not restored.

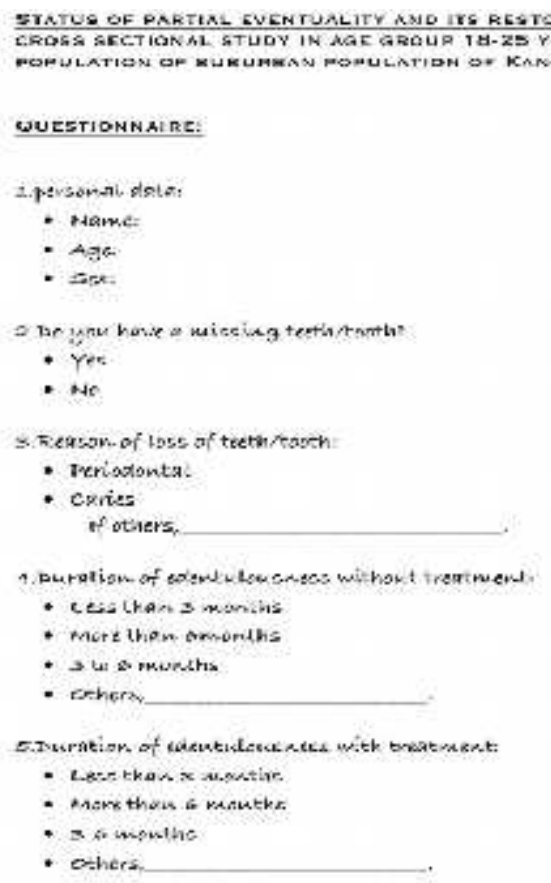

Figure 1

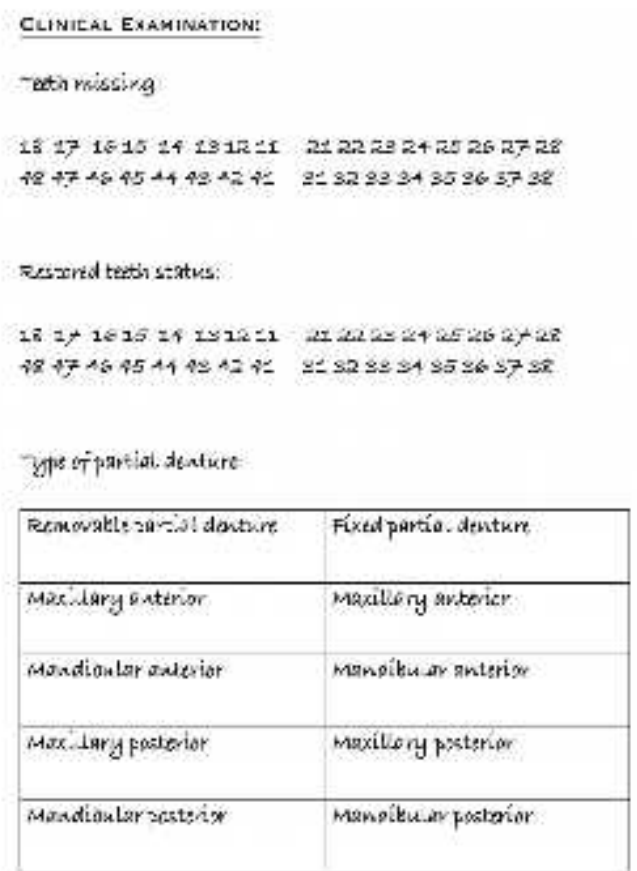

Figure 2 


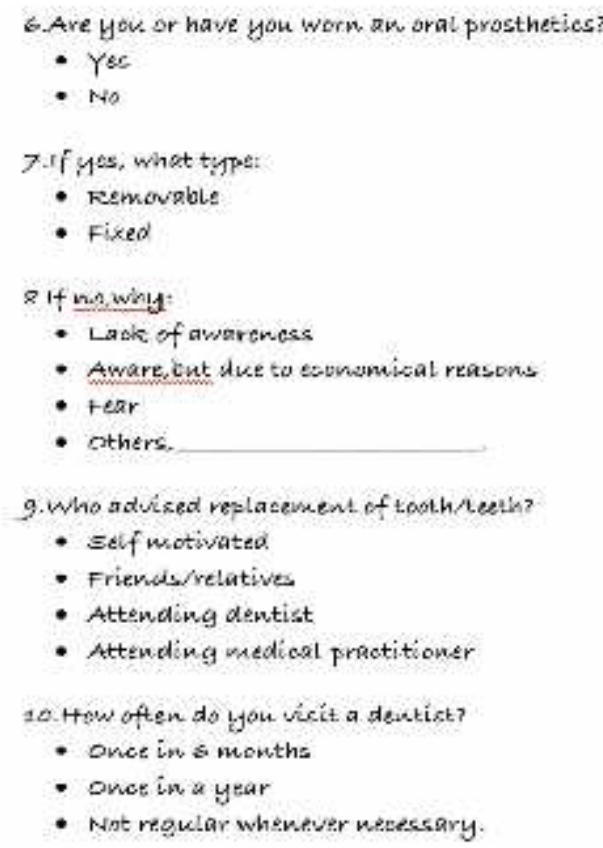

Figure 3

\section{Collection of data}

The questionnaire was conducted personally for each person who agreed to participate in the study in the form of an interview which appeared like normal conversation to allow for introduction and exploration of ideas deeply. Following the completion of interview the subject signed at the end of the questionnaire to mark their consent. (4)

\section{RESULT AND DISCUSSION}

Out of the 150 subjects 80 were male and 70 were females.The incidence of partial edentulism among the surveyed group was $23 \%$ with no significant gender based difference in the frequency of its occurence. A predominance of partial edentulousness in maxillary posterior region in men and mandibular posterior region of women.Lack of awareness to go for rehabilitation was seen in both groups. However, women subjects showed more awareness than men did. All the subjects preferred to undergo fixed partial denture treatment rather than removable options. This can be explained using (figure 4) where $27 \%$ of women out of affected cases had turned up for treatment when compared to men $(8 \%)$. All the restored subjects (both men and women) preferred fixed dentures than the removable ones (figure 5). Another important finding of this study was the predominance of maxillary posterior edentulousness in men and mandibular posterior edentulousness in women. The reason at present is unknown and would require further studies.

Dolan et al conducted a study about risk indicators of edentulism, partial tooth loss and prosthetic status among black and white middle aged and older adults through interview and dental examination. He concluded that people who had poor general health was significantly associated with edentulism and the blacks were less likely to receive prosthetic crowns.(2) Dr.AL-Dwairi also conducted a study on frequency of partial edentulism and removable denture construction among Jordanians. This study investigated the frequency of different classes of patterns of partial edentulism and the most frequently used design components of conventional cobalt-chromium RPD constructed for patients.(3) Though cross sectional surveys provide information on the extent and demographic distribution of tooth loss at one time, such survey cannot estimate trends in tooth loss. Detection of trends in a population requires longitudinal studies during which the same individuals are observed on more than one occasion. $(1,2,3)$
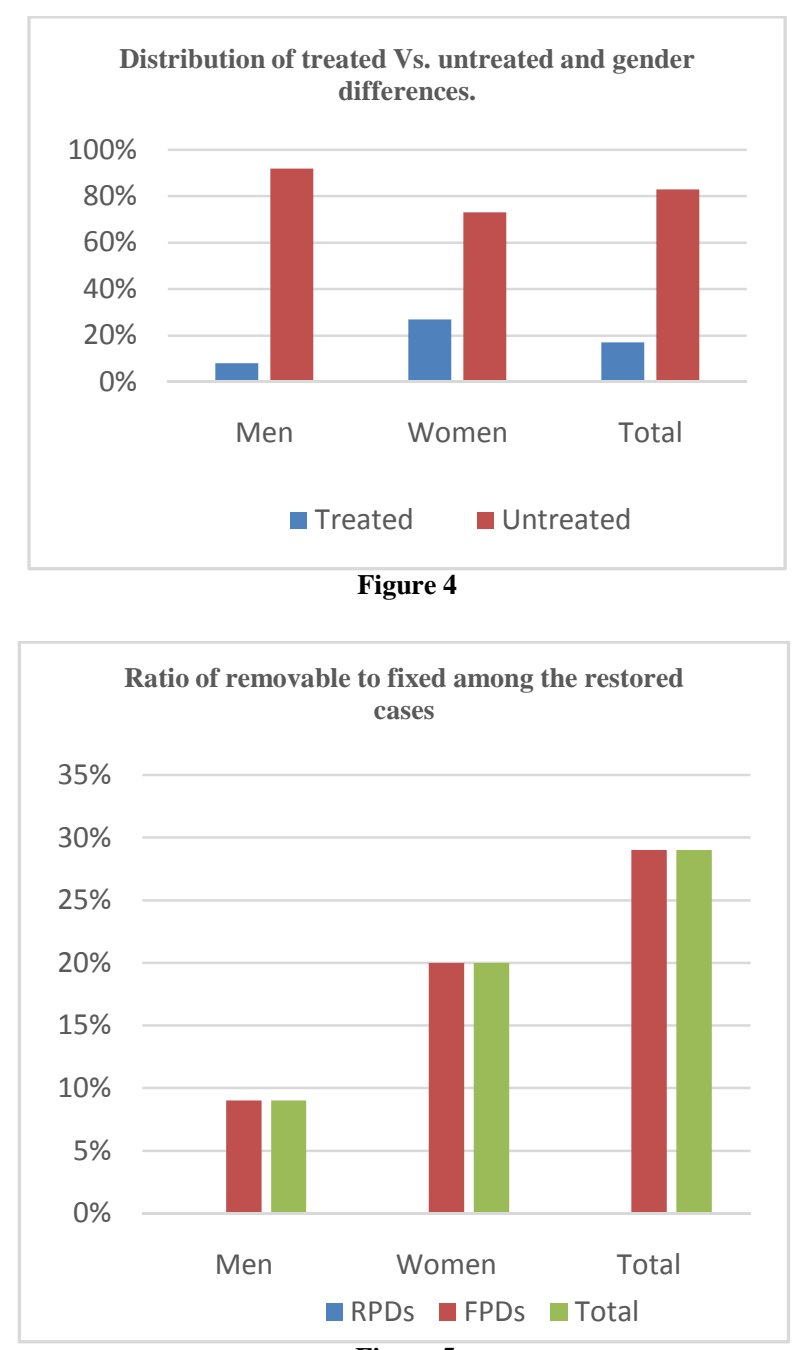

Figure 5

Dolan et al conducted a study about risk indicators of edentulism, partial tooth loss and prosthetic status among black and white middle aged and older adults through interview and dental examination. He concluded that people who had poor general health was significantly associated with edentulism and the blacks were less likely to receive prosthetic crowns.(2) Dr.AL-Dwairi also conducted a study on frequency of partial edentulism and removable denture construction among Jordanians. This study investigated the frequency of different classes of patterns of partial edentulism and the most frequently used design components of conventional cobalt-chromium RPD constructed for patients.(3) Though cross sectional surveys provide information on the extent and demographic distribution of tooth loss at one time, such survey cannot estimate trends in tooth loss. Detection of trends in a population requires longitudinal studies during which the same individuals are observed on more than one occasion. $(1,2,3)$ 


\section{CONCLUSION}

The loss of teeth can lead a patient to seek care for functional reasons as they notice a diminished function to a level that is unacceptable to them. The level at which a patient finds function to be unacceptable varies among individuals. This variability increases with accelerating tooth loss.(4) Also, the aesthetic impact of tooth loss can be highly significant and may be more of a concern to a patient than loss of function. The finding of this survey justify the greater need to educate the younger generation regarding the importance of tooth/teeth, treatment of diseased tooth/teeth and also to replace the same in-case if it has to be extracted due to any reasons(6).

\section{References}

Brown LJ. Trends in tooth loss among U.S. employed adults from 1971 to 1985. J Am Dent Assoc. 1994

Dolan TA, Gilbert GH, Duncan RP, Foerster U. Risk indicators of edentulism, partial tooth loss and prosthetic status among black and white middle-aged and older adults. Community Dent Oral Epidemical. 200
AL-Dwairi ZN. Partial edentulism and removable denture construction: a frequency study in Jordanians. Eur $J$ Prosthodont Restor Dent. 2006

Frequency of Partial Edentulism and Awareness to Restore the Same: A Cross Sectional Study in the Age Group of 18-25 Years Among Kerala Student Population,V. T. Abdurahiman, M. Abdul Khader, and Sanju John Jolly

Zitzmann NU, Marinello CP, Zemp E. Tooth loss, dental restorations and dental attendance in Switzerland. Schweiz Monatsschr Zahnmed.

Eklund SA, Burt BA. Risk factors for total tooth loss in the United States; longitudinal analysis of national data. $J$ Public Health Dent. 1994

Osterberg T, Dey DK, Sundh V, Carlsson GE, Jansson JO, Mellstrom D. Edentulism associated with obesity: a study of four national surveys of 16416 Swedes aged 55- 84 years. Acta Odontol Scand. 2010

Bokhout B, Hofman FX, Van Limbeek J, et al. Incidence of dental caries in the primary dentition in children with a cleft lip and/or palate. Caries Res. 1997

Bengtsson A, Olsson T, Rene N. Frequency of edentulism and identification marking of removable dentures in long term care units. J Ora rehabilitation. .

Kumari P, Kuriakose S (2002) The prevalence of crowding, midline discrepancies and premature tooth loss in primary dentition of children in age group 3-8 years

\section{Please cite this article in press as:}

Anjana Gopinath and Dr.Dhanraj (2017), Status of partial edentulism and its restoration:a study in the age group of 18-25 years among the sub-urban population of kanchipuram, International Journal of Current Advanced Research, 6(3), pp. 2699-2702. http://dx.doi.org/10.24327/ijcar.2017. 2702.0081 